\title{
Artificial insemination field data on the use of sexed and conventional semen in nulliparous Holstein heifers
}

\author{
A. A. Healy, ${ }^{* 1}$ J. K. House, $\dagger$ and P. C. Thomson $\ddagger$ \\ ${ }^{*}$ Faculty of Veterinary Science, University of Sydney, \\ †Livestock Veterinary Teaching and Research Unit, Faculty of Veterinary Science, University of Sydney, and \\ $\ddagger$ ReproGen - Animal Bioscience Group, Faculty of Veterinary Science, University of Sydney, Sydney 2570, Australia
}

\section{ABSTRACT}

This study investigated conception rates and other reproductive outcomes achieved with artificial insemination (AI) of nulliparous Holstein heifers using sexed and conventional semen in a commercial Australian dairy herd in central western New South Wales from January 2004 to April 2009. Retrospective data from on-farm records of 9,870 inseminations of 4,456 heifers were analyzed using several mixed models to assess the effect of temperature and humidity surrounding breeding, insemination sire, artificial insemination technician, service number, and heifer weight and age at breeding on reproductive traits (conception rates, sex ratios, gestation length, and abortion and stillbirth rates). Semen was used from 15 sexed sires and 41 unsexed sires. Sexed semen was primarily used at first and second service. Empirical conception rates of 31.6 and $39.6 \%$ were achieved for sexed and unsexed semen respectively, whereas model-based predictions were lower, at 21.3 and $32.1 \%$. Conception rates were significantly affected by insemination sire, sex-sorting, heifer age at breeding, temperature and humidity surrounding breeding, service number, and AI technician. Sexed semen yielded $86 \%$ heifers, compared with $48 \%$ for conventional semen. Significant predictors of calf sex included semen sexing, gestation length, and insemination sire. Twinning rate was high, at $3.6 \%$ for both semen types, and gestation length and heifer weight at breeding were significant predictors of twinning. Abortion rates for sexed and unsexed conceptions were similar at 6.1 and $6.5 \%$, respectively, and were affected by heifer age at breeding. Stillbirth rate was affected by calf sex, twinning, gestation length, and AI technician; semen sorting, age at breeding, and temperature and humidity were marginally significant predictors. No abnormalities were observed in the development of offspring, except for a marginally higher stillbirth rate for sexed calves, a finding that needs further investiga-

Received February 23, 2012.

Accepted November 12, 2012

${ }^{1}$ Corresponding author: abur9715@uni.sydney.edu.au tion. Many variables influence the breeding outcomes associated with the application of sex-sorted sperm on commercial dairy farms. Recognition and management of these variables will increase the economic return from the investment in sex-sorted sperm.

Key words: sexed semen, conception rate, dairy heifer, artificial insemination

\section{INTRODUCTION}

The availability of genetically desirable replacement heifers significantly influences the profitability of a dairy enterprise. Sex-sorted semen allows farmers to significantly skew the sex ratio of their animals' offspring, so herd reproductive management is no longer limited by balancing the need for an adequate supply of replacement heifers against the necessity of achieving pregnancies to start new lactations (De Vries et al., 2008). Sex preselection will accelerate genetic gain, improve herd biosecurity, and reduce the incidence of dystocia and the number of superfluous bull calvesa major industry welfare issue. Fewer cows would be required to produce daughters for progeny testing, and greater opportunity would exist for cross-breeding of older, genetically inferior cows, because a steady supply of genetically superior replacement heifers is ensured (Hohenboken, 1999; Seidel, 2002, 2007).

Flow cytometry is currently the fastest and most reliable method of sperm sorting, yet it is still slow relative to the daily semen requirement of commercial dairy herds. Individual sperm are differentiated based on the amount of DNA in each spermatozoon, because sperm bearing an $\mathrm{X}$ chromosome contain approximately 3.8\% more DNA than their Y-bearing counterparts (Weigel, 2004; Garner, 2006; Garner and Seidel, 2008). Bull semen copes better with sorting and freezing and has a greater DNA differential than semen of most other domestic species, so it is more easily sorted and yields better conception rates (Garner, 2006; Vazquez et al., 2008). Yet almost all the sperm are wasted, sex differentiation is not completely accurate, sorting is slow, and the viability, motility, lifespan, and consequently 
fertilizing ability are compromised (Vazquez et al., 2008).

Low sperm throughput means it is economically necessary to use much lower insemination doses of sexed semen. The scientific consensus is that $2 \times 10^{6}$ sperm per dose provides the optimal balance between commercially acceptable conception rates and the increased cost of sexed semen (Weigel, 2004; Seidel, 2008; Seidel and Schenk, 2008; Vazquez et al., 2008). A conventional sperm dose normally contains 15 to $20 \times 10^{6}$ sperm (Andersson et al., 2004; Seidel, 2007). Low sperm dose and reduced sperm fertility both affect the outcome of insemination, but it is yet to be proven which has the greater influence.

Currently, limited data are available on the performance of sexed semen in commercial Australian dairy herds. The objective of this retrospective study was to compare sexed and unsexed semen use for year-round AI of heifers, in terms of conception rate, sex ratio, gestation length, twinning, abortion and stillbirth rate, and to determine the effect of herd management and environmental variables on conception rates achieved with sexed and unsexed semen.

\section{MATERIALS AND METHODS}

\section{Study Design, Animals, and Housing}

Retrospective data were collected from January 2004 until April 2009 on 9,870 inseminations of 4,456 nulliparous Holstein heifers reared in a single, commercial dairy herd in central western New South Wales. The heifers were paddock-raised, grouped according to height and weight, and fed mixed rations to meet all or part of their nutritional requirements according to pasture availability. All of the heifers enrolled in the breeding program were grouped together and, as such, minimal differences exist between these heifers regarding paddock conditions and nutrition. Heifers were nutritionally managed to attain an average daily gain of 0.8 to $1.0 \mathrm{~kg} / \mathrm{d}$ from birth to breeding.

\section{Reproductive Management}

First-service heifers were administered 2 injections of $2 \mathrm{~mL}$ of $\mathrm{PGF}_{2 \alpha}$ (Lutalyse, Pfizer Sydney, New South Wales, Australia) $14 \mathrm{~d}$ apart and then inseminated based on the activation of a heat detection device (Kamar, San Diego, CA) as an indicator of standing estrus. Artificial insemination was performed once daily, on the same morning as estrus detection. For all subsequent services, heifers were bred upon display of a natural standing estrus with no synchronization. Insemination was carried out by 9 AI technicians us-

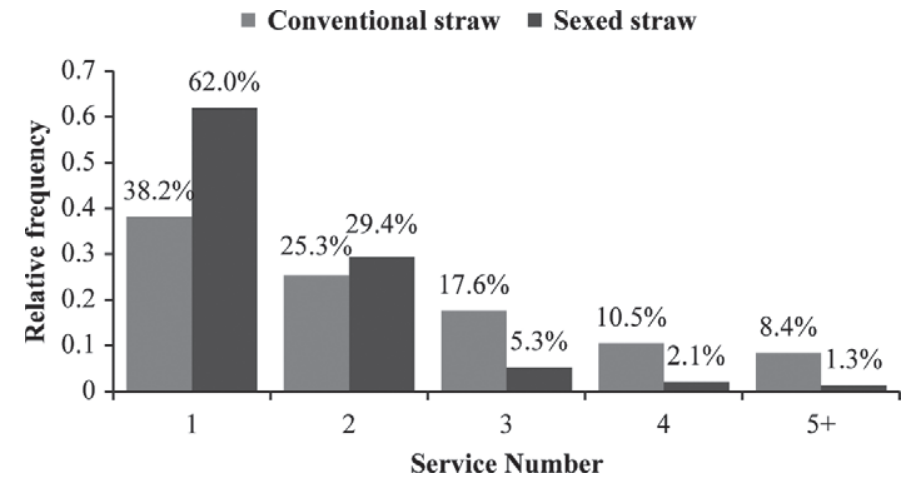

Figure 1. Relative frequency of inseminations within semen type per service number.

ing sexed and unsexed semen straws collected from 56 dairy sires, provided by ABS Australia (Table Top, New South Wales, Australia) and sorted by flow cytometry at ABS Global in DeForest, Wisconsin. All 56 sires were selected for calving ease. Some selection was performed based on bull fertility, but only to the extent that bulls with demonstrably lower conception rates were no longer used.

Sperm viability and semen quality were not evaluated before insemination and as such, the results reflect normal on-farm reproductive management. In most cases, sex-sorted straws were used only for the first or second breeding and heifers returning to estrus were inseminated with conventional semen for subsequent breedings (Figure 1). Occasionally, heifers were bred more than twice with sexed semen.

The insemination site for all breedings was the uterine body. Inseminated heifers were tested for pregnancy via rectal palpation from 40 to $50 \mathrm{~d}$ postinsemination, and nonpregnant heifers were inseminated again upon return to estrus. Heifers displaying signs of estrus after a positive pregnancy check were palpated again and if a heifer was found to be nonpregnant, the original conception was listed as an abortion.

\section{Environmental Conditions}

Daily climatic data were obtained from the Australian Bureau of Meteorology weather stations at Cowra and Forbes for the period from January 2004 until April 2009. The farm was located halfway (approximately 30 $\mathrm{km}$ from each) between these weather stations, so the daily temperature and relative humidity at 0900 and $1500 \mathrm{~h}$ from each station were averaged to provide a proxy for the temperature and humidity conditions on the farm. These data were then used to determine the $0900 \mathrm{~h}$ average temperature-humidity index (THI) for the $3 \mathrm{~d}$ following breeding (National Oceanic and Atmospheric Administration, 1976): 


$$
\begin{gathered}
\mathrm{THI}=\left(9 / 5 \text { temperature }{ }^{\circ} \mathrm{C}+32\right)-(11 / 2-11 / 2 \\
\times \text { humidity }) \times\left(9 / 5 \text { temperature }{ }^{\circ} \mathrm{C}-26\right) .
\end{gathered}
$$

\section{Available Data}

A total of 2,718 sexed inseminations and 7,152 unsexed inseminations were performed during the period of this study using 15 sexed sires (range of 1-651 inseminations) and 41 conventional sires (range of 1-784 inseminations). This resulted in 2,689 births and 188 abortions. Available data for analysis included heifer identity and birth date, insemination date and sire, weight at breeding (average $431 \mathrm{~kg}$, range 301-888 $\mathrm{kg}$ ), service number, semen sexing, AI technician, local temperature and humidity at breeding, conception success, conception date, abortion date, gestation length, sex of offspring, and incidence of twins and stillbirths. Summary statistics for the continuous variables are presented in Table 1.

\section{Data Editing}

Conceptions attributed to natural matings were removed to ensure only artificial inseminations were included. The categorical variable service number was reduced from 6 levels to 5 to increase statistical power because very few heifers were bred more than 5 times. A normal gestation length was defined as ranging from 249 to 305 d (3 standard deviations either side of the mean gestation of $277.6 \mathrm{~d}$ ). Any conception with a gestation length $<249 \mathrm{~d}$ was designated an abortion. Histograms of age and weight at breeding were created and any outliers deleted from the analysis as assumed recording errors. Weight at breeding needed to be approximated for heifers not weighed on the same day as insemination, assuming an average daily gain of 0.8 $\mathrm{kg} / \mathrm{d}$ (Chebel et al., 2007). To calculate an estimated breeding weight, the interval between breeding and last weighing was multiplied by average daily gain and then added to the heifer's last recorded weight. To determine accurate sex ratios, only births with gestation lengths of 249 to 305 d were included to eliminate inaccuracies in the sex ratio due to the possibility of incorrect sire identification.

\section{Statistical Analysis}

Statistical analysis was performed with GenStat software (11th edition, VSN International, Hemel Hempstead, UK). A generalized linear mixed model (GLMM) was used to evaluate the effect of numerous predictors on the odds of conception. Semen-sexing, heifer weight $(\mathrm{kg})$ and age at breeding (d), insemination sire, average $0900 \mathrm{~h}$ THI $3 \mathrm{~d}$ postbreeding, and AI technician were all investigated as possible sources of variation in conception rate. Initially, several logistic regression models were fitted by including in the analysis the random effect of the inseminating sire and one explanatory variable, treated as a fixed effect, at a time. Predictors with a significant or suggestive $(P$ $<0.1$ ) effect on conception rate and their interactions were considered further for the definition of the final model. This model included the effect of the inseminating sire and the explanatory variables that a stepwise procedure selected within the group of significant predictors of conception rate. Sire identification was also included as a random effect in these models.

The effect of insemination sire on breeding outcome was assessed by $z$-test to compare the size of the estimated variance component relative to the standard error. From this, an approximate $P$-value was calculated as a means of assessing significance.

A GLMM was also fitted to assess the effect of suspected predictors on abortion and stillbirth rate, with sire included in the model as a random effect. Suspected predictors included semen sorting, THI, age and weight at breeding, AI technician, and service number, with twinning and gestation length also included for stillbirth rate. Abortion was defined as any heifer that was pregnancy tested in calf and either failed to calve or returned to estrus and was then palpated and determined not to be pregnant, and any heifer that was observed to expel a fetus or fetal membranes at a gestation length $<249$ d. Significant or suggestive predictors $(P<0.1)$ were included in the final regression model for both stillbirth and abortion. The significance of some predictors of stillbirth rate varied, depending on whether the analysis included only singleton births or both singleton and twin births. Consequently, a separate GLMM was used to assess predictors of stillbirth for singleton

Table 1. Summary statistics for continuous predictor variables

\begin{tabular}{lcccc}
\hline Source & 1st Percentile & 99th Percentile & Mean & Median \\
\hline Breeding age (d) & 347 & 645.52 & 456.4 & 449 \\
Breeding weight (kg) & 345.6 & 606.64 & 430 & 421 \\
Gestation length (d) & 254.25 & 305 & 277.6 & 278 \\
Average 0900 $\mathrm{hHI}^{1}$ 3 d postbreeding & 29.83 & 68.37 & 50.46 & 51.33 \\
\hline
\end{tabular}

${ }^{1}$ Temperature-humidity index. 
Table 2. Significant predictors of conception rate

\begin{tabular}{lccccc}
\hline Predictor & $\begin{array}{c}\text { Wald } \\
\text { statistic }\end{array}$ & df & $P$-value & $\begin{array}{c}\text { Odds } \\
\text { ratio }\end{array}$ & $95 \%$ CI \\
\hline AI technician & 45.97 & 8 & $<0.001$ & - & - \\
AI technician $\times$ age at breeding & 23.81 & 8 & 0.024 & - & - \\
Service number & 88.01 & 4 & $<0.001$ & - & - \\
Semen type & 12.49 & 1 & $<0.001$ & 0.57 & $0.42-0.78$ \\
Average 0900 h $\mathrm{THI}^{1} 3 \mathrm{~d}$ postbreeding (10 units) & 15.78 & 1 & $<0.001$ & 0.91 & $0.87-0.95$ \\
\hline
\end{tabular}

${ }^{1}$ Temperature-humidity index.

births only, and then another GLMM to assess predictors of stillbirth for twin and singleton births.

Possible predictors of gestation length were detected through a linear mixed model, including the random effect of the inseminating sire and the fixed effect of one explanatory variable at a time. Significant predictors included calf sex, AI technician, type of semen, incidence of twins, THI, and heifer age and weight at breeding. These predictors were considered for inclusion in the final model. The aim was to determine factors that either prolong or shorten a "normal" gestation length so only conceptions with gestation lengths ranging from 249 to $305 \mathrm{~d}$ were included in the model, to exclude confounding factors that result in abnormally short gestation lengths (i.e., abortions). This reduced the number of sires from 56 to 45, excluding sires that did not achieve a conception, achieved a pregnancy that resulted in abortion, or did not have gestation lengths recorded for any offspring.

A $\chi^{2}$ test for a contingency table was performed to investigate associations between calf sex, twinning, sire, AI technician, semen sorting, temperature, and humidity and incidence of stillbirths and abortions. The $\chi^{2}$ analysis for insemination sire required omitting 12 of 56 sires because of low progeny numbers and consequent low expected frequency in the test.

\section{RESULTS}

\section{Conception Rates}

The empirical conception rates were $31.6 \%$ for sexed semen and $39.6 \%$ for conventional semen. Sex-sorting, heifer age at breeding, THI, AI technician, service number, and insemination sire all had a highly significant $(P<0.001)$ effect on conception rate (Table 2$)$. The conception rates predicted by the GLMM were lower than those calculated from the raw data, being $21.3 \%$ for sexed semen and $32.1 \%$ for conventional semen, having taken into account variation due to the significant predictors that were included in the final multivariable model. Insemination sire had a significant effect on conception rate $(P<0.0001)$. The minimum and maximum conception rates were 10 and $35.5 \%$ for sexed sires and 12.3 and $39.5 \%$ for conventional sires, respectively.

The relationship between average $0900 \mathrm{~h}$ THI $3 \mathrm{~d}$ postbreeding and conception rate was approximately linear (Figure 2). The odds of conception are multiplied by 0.91 for every 10 -unit increase in THI, indicating an overall decline in conception rate with increasing THI (Table 2). Conception rate for both semen types was numerically greatest at first service and declined with each subsequent breeding (Figure 3).

Heifer weight at breeding ranged from 301 to 888 $\mathrm{kg}(\mathrm{SD}: 52 \mathrm{~kg})$ and was not a significant predictor of conception $(P=0.5)$. We observed a significant $(P=$ 0.024) interaction between AI technician and age at breeding: as age at breeding increased, the odds of a conception were reduced for most technicians, although the reverse trend was observed for 2 inseminators (Figure 4). Conception rate varied significantly with AI technician; the error bars represent the $95 \%$ CI calculated from the standard error (Figure 5). The number of inseminations performed by individual AI technicians varied significantly, which would affect the validity of the results specific to each technician (Figure 6).

\section{Sex Ratio}

The sex ratio for sexed-semen inseminations was $86 \%$ females for singleton births within a 249- to 305-d gestation interval. The sex ratio for unsorted semen was

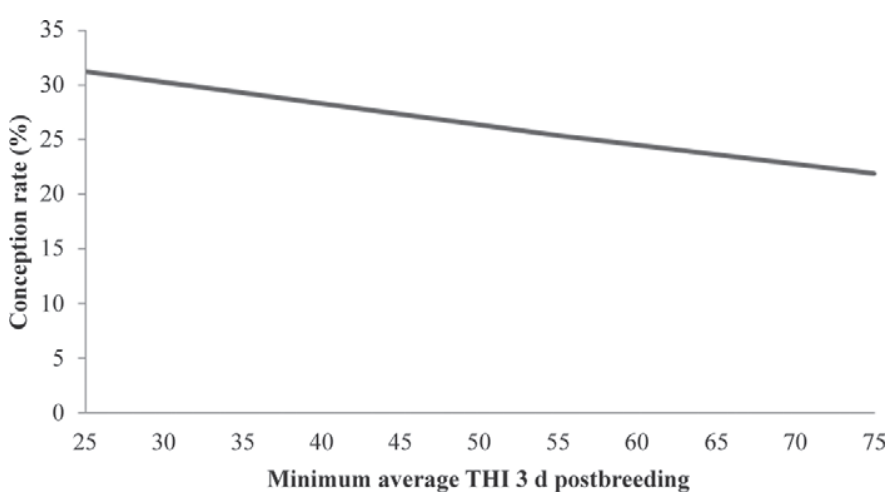

Figure 2. Effect of average $0900 \mathrm{~h}$ temperature-humidity index (THI) $3 \mathrm{~d}$ postbreeding on conception rates. 


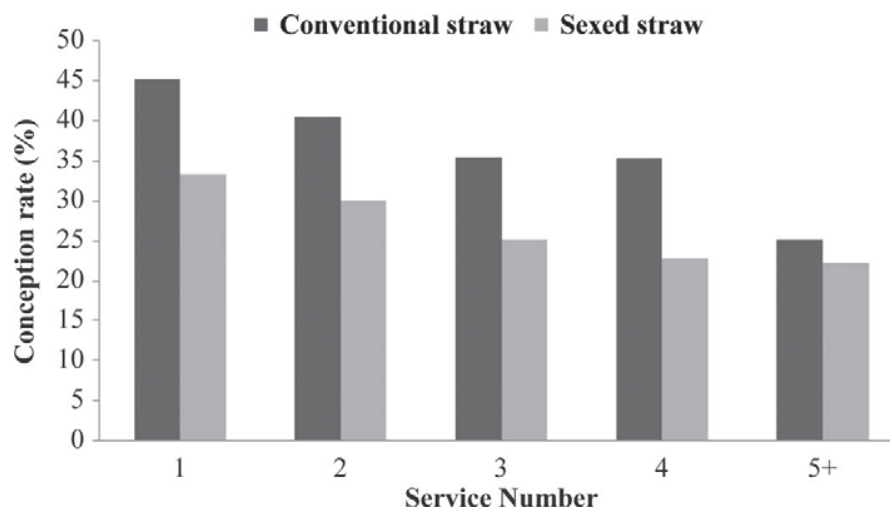

Figure 3. Empirical conception rates for sexed and conventional semen by service number.

$48 \%$ females for singleton births. Significant predictors of calf sex were semen sexing, gestation length $(P<$ $0.001)$, and insemination sire $(P=0.008$; Table 3$)$.

\section{Twinning}

The overall rate of twinning was $3.6 \%$. We found no association $(P=0.97)$ between semen sorting and an increased incidence of twinning. The only factors that significantly $(P<0.001)$ predicted the rate of twinning were gestation length and weight of the heifer at breeding. For a 1-d increase in gestation length, the odds of a twin birth decreased, being multiplied by $0.91(95 \%$ CI: 0.88 to 0.94$)$. For a $10-\mathrm{kg}$ increase in heifer weight at breeding, the odds of a twin birth increased, being multiplied by 1.06 (95\% CI: 1.02 to 1.09). Insemination sire did not have a significant effect on the rate of twin$\operatorname{ning}(P=0.38)$.

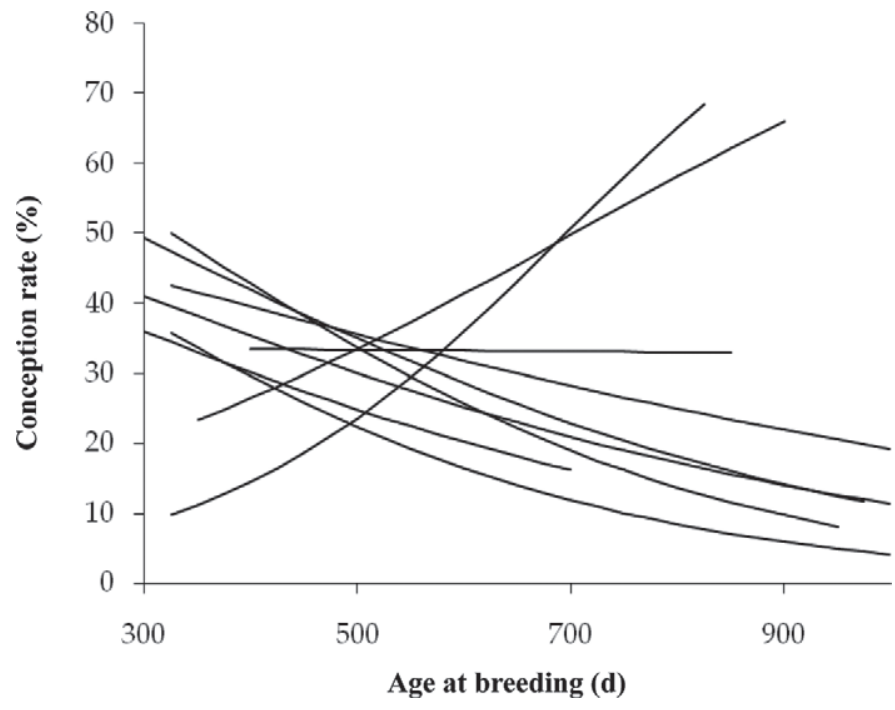

Figure 4. Effect of age at breeding on conception rate per AI technician.

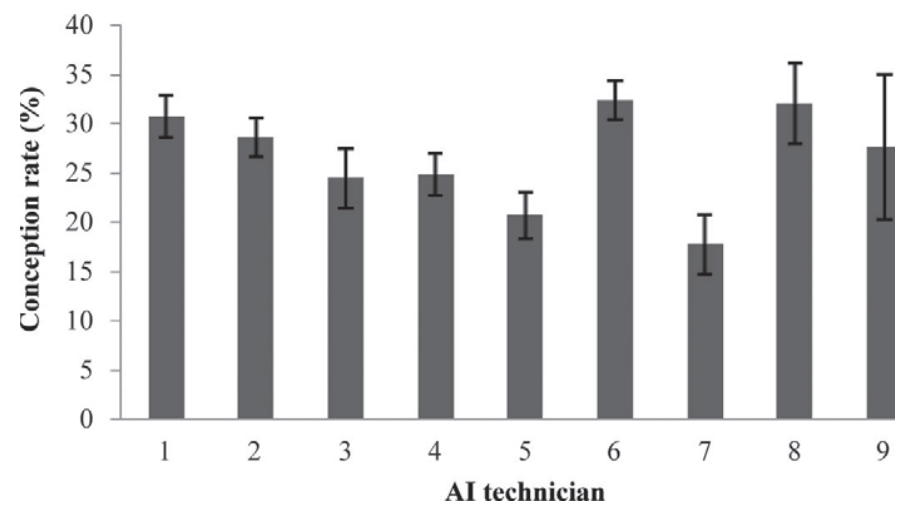

Figure 5. Conception rates for individual AI technician. The error bars represent the $95 \%$ confidence interval calculated from the standard error.

With regard to twin births to sexed-semen conceptions, $60 \%$ were both female, $30 \%$ mixed, and $10 \%$ both male. The sex ratio for twins to unsexed semen conceptions were $29 \%$ both female, $46 \%$ mixed, and $25 \%$ both male.

\section{Abortion Analysis}

There were 188 abortions in total. Abortion rates for sexed and unsexed semen were similar, at 6.1 and $6.5 \%$, respectively. Sex sorting, insemination sire, THI, AI technician, weight at breeding, and service number did not have a significant effect on abortion rate (all $P>0.1)$. The only factor with a significant effect $(P$ $=0.024$ ) was heifer age at breeding (Figure 7). For a 10-d increase in heifer age at conception, the odds of an abortion occurring was multiplied by 1.03 (95\% CI: $1.003-1.05)$.

\section{Gestation Length}

Significant factors $(P<0.05)$ affecting gestation length were calf sex, AI technician, insemination sire, incidence of twins, and THI. Regardless of calf sex, the gestation length for twin births was, on average, 4.4 d shorter than for singleton births, being 274.6 and $279.0 \mathrm{~d}$, respectively. Additionally, the gestation length for singleton female calves was $1.3 \mathrm{~d}$ less than that for singleton male calves, being 276.0 and $277.3 \mathrm{~d}$, respectively.

\section{Stillbirth Analysis}

Calf sex was significantly associated with stillbirth rate $(P=0.003)$, and the percentage of calves born dead was higher for singleton male calves than for singleton female calves for both sexed and unsexed offspring (Table 4). 


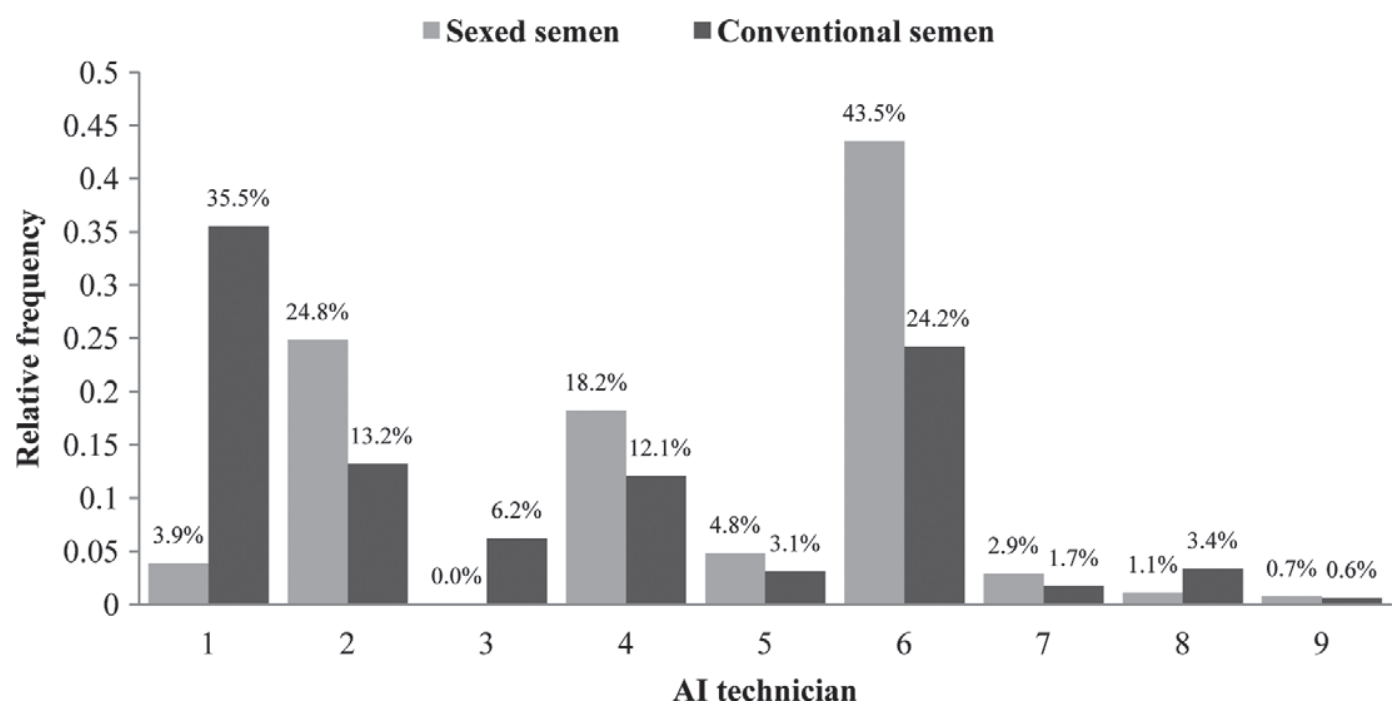

Figure 6. Relative frequency of inseminations per AI technician by semen type.

From the GLMM, sex-sorting of semen had a marginal effect $(P=0.051)$ on increasing the rate of stillbirths (Table 5). For singleton births, the estimated stillbirth rate was higher for sexed offspring than for unsexed offspring and was higher for males than for females. The average stillbirth rate adjusted for sex ratios was $11.66 \%$ for conventional semen and $13.3 \%$ for sexed semen.

Heifer weight at breeding did not have a significant effect on the incidence of stillbirths $(P=0.90)$. We detected a significant association between the incidence of stillbirths and twinning, gestation length, calf sex (all $P<0.001)$, and AI technician $(P=0.049$; Table 5).

We found a likely association between age at breeding $(P=0.082)$ and the incidence of stillbirths. Age at breeding exhibited an increased statistical significance as a predictor of stillbirth incidence when only singleton births were included in the model $(P=0.17$ vs. $P$ $=0.08)$. Likewise, THI had a more significant effect when only single births were included in the model $(P$ $=0.161$ vs. $P=0.061$ ).

\section{DISCUSSION}

\section{Conception Rates}

Conception rates achievable with sexed semen vary significantly across studies, which emphasizes the influence of on-farm factors. Conception rates can be affected by parity, age, body condition, sire selection, and accuracy of estrus detection (Seidel and Schenk, 2008). For both semen types, dairy heifers have inherently higher fertility and achieve consistently better conception rates than lactating cows (Donovan et al., 2003; Garner and Seidel, 2008; Seidel and Schenk, 2008). As such, sexed semen is recommended for use in heifers because they are more fertile, more prone to dystocia, and genetically superior, on average, compared with older cows of previous generations (Seidel, 2007).

The fertilizing ability of sexed sperm is thought to be reduced by flow cytometry sorting to 60 to $90 \%$ of that of unsorted sperm. This is substantiated by several studies in which the difference in conception rates for low-dose sexed and normal-dose unsexed semen in dairy heifers ranged from approximately 10 to 30\% (Seidel et al., 1999; Borchersen and Peacock, 2009; DeJarnette et al., 2009). However, first-service conception rates of greater than $50 \%$ have been reported in some field studies (Weigel, 2004; Cerchiaro et al., 2007; Borchersen and Peacock, 2009).

The first-service sexed semen conception rate observed in this study was lower than that for sexed-semen AI of dairy heifers overseas, which range from 39 to

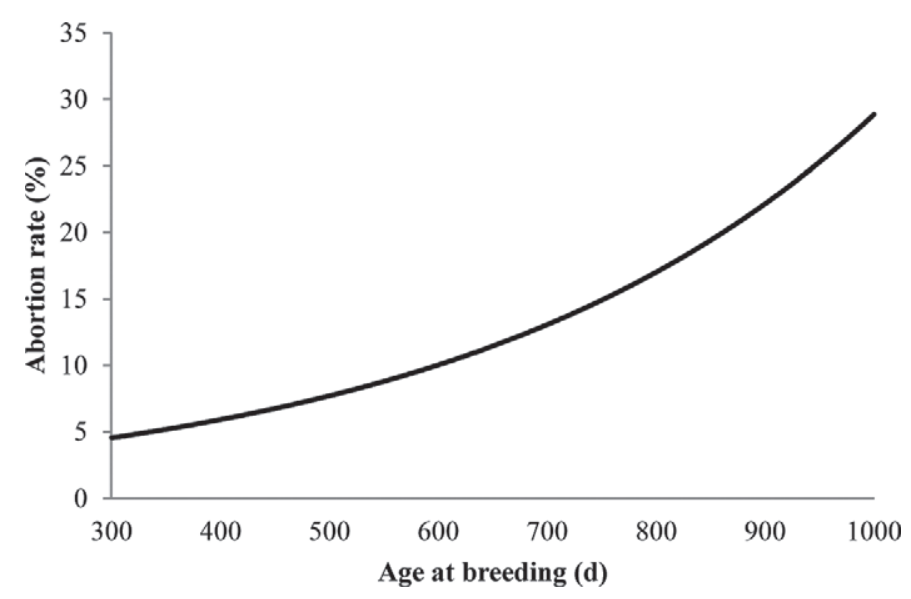

Figure 7. Effect of heifer age at breeding on abortion rate. 
Table 3. Significant predictors of a female calf

\begin{tabular}{lccccc}
\hline Predictor & $\begin{array}{c}\text { Wald } \\
\text { statistic }\end{array}$ & df & $P$-value & $\begin{array}{c}\text { Odds } \\
\text { ratio }\end{array}$ & $95 \%$ CI \\
\hline Semen type & 72.75 & 1 & $<0.001$ & 6.33 & $4.1-9.8$ \\
Gestation length (d) & 30.55 & 1 & $<0.001$ & 0.97 & $0.96-0.98$ \\
\hline
\end{tabular}

57\% (Cerchiaro et al., 2007; Borchersen and Peacock, 2009; DeJarnette et al., 2009). In the present study, sexed semen fertility was similar to that reported by Bodmer et al. (2005) and Weigel (2004). It was, however, within $80 \%$ of the conventional semen conception rate, a commonly reported finding (Seidel and Garner, 2002; Borchersen and Peacock, 2009; DeJarnette et al., 2009). In contrast, Norman et al. (2010) found that when used in heifers sexed semen was only $69 \%$ as fertile as conventional semen at first service, a finding that is closer to the model-based predictions in the current study. Similarly, Bodmer et al. (2005) encountered even lower fertility, at $56 \%$ of unsorted sperm.

The first-service conventional semen conception rate observed in this study was lower than the industry target for Holstein females, regardless of parity, and was also lower than the rate in most reports in the literature for virgin heifers, which ranges from 48 to $76 \%$ (Bodmer et al., 2005; Stevenson et al., 2006; DeJarnette et al., 2009). It was slightly lower than that reported by Donovan et al. (2003). Unsorted inseminations acted as control inseminations, establishing baseline fertility for the herd and inseminators. Low unsexed conception rates implied that the reproductive performance of a particular herd was suboptimal compared with results achieved in other countries. For example, synchronization with PGF has been linked to reduced conception rates (Donovan et al., 2003). Because sexed straws were used preferentially at first service in the current study, a greater percentage of sexed inseminations were to PGF-synchronized heifers, which may have diminished conception rates. Additionally, many of the international studies were undertaken in more moderate climates. In the United States, Norman et al. (2010) established a mean heifer conception rate of $56 \%$ for conventional semen and $39 \%$ for sexed semen, indicating a higher overall fertility than the herd examined in this study. It could be expected that conception rates will be lower in an Australian year-round-calving dairy herd subjected to a hotter climate for several months of the year.

The effect of service number on decreasing conception rates was similar for sexed and nonsexed inseminations. Decreasing conception rates with increasing service number was in agreement with the literature (DeJarnette et al., 2009; Norman et al., 2010) and implies that heifers that required repeated breedings were inherently less fertile. Therefore, sexed straws should be reserved for the first and second services because the significant reduction in conception rate associated with increased service number results in low cost-to-benefit ratios for farmers.

Low conception rates are a function of diminished fertilizing ability due to sperm damage incurred during sorting, as well as the reduced dose used. Additionally, Seidel et al. (1999) reported a possible link between sex-sorted sperm and an increased rate of early embryonic death, which could exacerbate the aforementioned effects on conception rate. Several authors postulate that low conception rates are primarily a function of low sperm dose (Bodmer et al., 2005; Frijters et al., 2009). Therefore, if the efficiency of sorting were improved, it would allow use of higher insemination doses. Increased cost-to-benefit may lead to more widespread use in commercial dairies.

The conception rates predicted by the multivariable model were lower than the raw conception rates achieved on farm. This is because the multivariable model adjusted for all significant factors to allow an even comparison of fertility between sexed and unsexed semen. By extension, the model-based predictions adjusted for local on-farm efforts to improve reproductive performance, such as preferential use of sexed straws at first service and more experienced AI technicians performing sexed-semen inseminations. These management strategies mean that heifers bred to sexed semen have a better chance of conceiving compared with heif-

Table 4. Empirical incidence (\%) of stillbirths for singleton calves born to sexed and conventional semen

\begin{tabular}{llrcc}
\hline Semen type & Calf sex & $\begin{array}{c}\text { Born } \\
(\text { no. })\end{array}$ & $\begin{array}{c}\text { Stillborn } \\
(\%)\end{array}$ & $\begin{array}{c}\text { Stillborn by } \\
\text { semen type (\%) }\end{array}$ \\
\hline Sexed & Female & 472 & 12.9 & 13.3 \\
Conventional & Male & 76 & 15.8 & 11.65 \\
& Female & 1,037 & 9.1 & \\
\hline
\end{tabular}


Table 5. Significant predictors of stillbirth rate

\begin{tabular}{lccccc}
\hline Predictor & $\begin{array}{c}\text { Wald } \\
\text { statistic }\end{array}$ & df & $P$-value & $\begin{array}{c}\text { Odds } \\
\text { ratio }\end{array}$ & $95 \%$ CI \\
\hline Twin birth & 29.20 & 1 & $<0.001$ & 3.42 & $2.17-5.39$ \\
Gestation length $(10 \mathrm{~d})$ & 42.73 & 1 & $<0.001$ & 0.94 & $0.93-0.96$ \\
Calf sex & 14.01 & 1 & $<0.001$ & 1.56 & $1.23-1.99$ \\
AI technician & 15.55 & 8 & 0.049 & - & - \\
Semen type & 3.79 & 1 & 0.051 & 1.38 & $0.99-1.92$ \\
Average 0900 h THI 3 d postbreeding & 3.51 & 1 & 0.061 & $1.12^{1}$ & $1.1-1.13^{1}$ \\
Age at breeding $(\mathrm{d})^{2}$ & 3.02 & 1 & 0.082 & 0.98 & $0.978-0.983$ \\
${ }^{1}$ Calculated for an increase in temperature-humidity index (THI) of 10 units. & & \\
${ }^{2}$ Only significant when twin births were excluded from analysis. & & &
\end{tabular}

ers bred to conventional semen. The observed difference between the model-based predictions and the raw data and the fact that sexed conception rates are closer to conventional conception rates based on the raw data may imply that preferential on-farm management strategies to increase sexed semen fertility are effective.

Older heifers were less likely to conceive than younger heifers for both semen types. This effect did not reflect the effect of BW, which was found to have a negligible effect on conception outcome, similar to findings in other studies (Donovan et al., 2003; Chebel et al., 2007). Previous studies have found no association between age at first service and conception rate for nulliparous Holstein heifers with either semen type (Donovan et al., 2003; Cerchiaro et al., 2007). The interaction between age at breeding and AI technician was interesting: 2 of the $9 \mathrm{AI}$ technicians defied the trend and achieved better conception rates as the heifers increased in age. These 2 technicians performed a relatively small number of inseminations and so a possible explanation is the inexperience of the inseminators relative to the maturity of the reproductive tract.

Several studies have documented how conception rate is reduced when heifers are inseminated during warmer months or during particularly hot seasons (Donovan et al., 2003; Cerchiaro et al., 2007). A significant decrease in conception rate of approximately $10 \%$ was observed between the maximum and minimum recorded $0900 \mathrm{~h}$ average THI 3 d postbreeding, which has major implications for the effect of local temperature and humidity on fertility. Based on these results and because of the expense of sexed straws, it is recommended that their use be reserved for milder climatic conditions to maximize conception rates and provide the greatest cost-tobenefit for producers.

Insemination sire significantly affected conception rate for both semen types, as reported in the literature (Cerchiaro et al., 2007; Chebel et al., 2007; Frijters et al., 2009). The variation in conception rate attributed solely to insemination sire was large, equating to a difference of up $25.5 \%$. This emphasizes the differences between the inherent fertility of individual bulls, as well as differences in the ability of individual bulls to withstand sorting.

\section{Sex Ratios}

The purity of sexed semen in this study was acceptable and similar to that reported by Bodmer et al. (2005) and Tubman et al. (2004). However, it was slightly lower than the majority of reports in the literature, which are closer to $90 \%$ (Cerchiaro et al., 2007; DeJarnette et al., 2009; Norman et al., 2010). This may reflect either errors in recording of semen type or calf sex or reduced accuracy of sorting, which can be a result of increased sorting speed (Seidel, 2003). The sex ratio for conventional semen was in accordance with most trials, which achieve approximately 50 to $52 \%$ males (Tubman et al., 2004; DeJarnette et al., 2009). However, Norman et al. (2010) observed only $48.5 \%$ single males born to heifer dams. Insemination sire within semen type was also a significant predictor of calf sex-individual bulls may differ in the ease with which their sperm is sexed and thus yield sexed straws of greater purity.

\section{Twinning}

The rate of twinning in the present study was higher than the expected rate for nulliparous Holstein heifers. The twinning rate for nulliparous Holstein heifers has previously been reported to range from 1.1 to $1.3 \%$ (Erb and Morrison, 1959; Silva del Rio et al., 2007; Norman et al., 2010). The weight of the heifer at breeding significantly affected the incidence of twins, with heavier heifers more prone to twinning. Sex-sorting had no effect on the incidence of twin births in this study, but it did affect the sex ratio of twin offspring.

\section{Abortion}

The abortion rates for sexed and unsexed semen were similar. This is in agreement with other studies that report identical stillbirth and abortion rates for sexed 
and conventional semen (Tubman et al., 2004; Seidel, 2007; DeJarnette et al., 2009). These results imply that, despite legitimate concerns about the potential damage incurred by sperm DNA during the sorting process, abortion is not a biological consequence and so the damage sustained is likely to be minimal. Considering the increased rate of stillbirths observed in this study and conflicting reports in the literature, it would be prudent to investigate the variation of viability of sexed offspring further to ascertain if this finding is repeatable and if sorting has an actual effect on the viability of sexed offspring.

\section{Gestation Length}

The results for gestation length were in accordance with several studies reporting that gestation length in dairy cattle is affected by parity, season, sire, the incidence of twins, and calf sex (Fisher and Williams, 1978; DeJarnette et al., 2009; Norman et al., 2009). Apart from the effect on calf sex, semen sorting did not significantly attenuate or prolong gestation length, in agreement with Tubman et al. (2004).

\section{Stillbirths}

The stillbirth rates for singleton births born to heifers inseminated with sexed and conventional semen were both higher than the reported stillbirth rate of $8.3 \%$ for conventional semen in some studies (Mangurkar et al., 1984). This may be a result of peripartum management of the heifers particular to this herd (e.g., delayed intervention during dystocia). However, the stillbirth rate for conventional semen was similar to that reported by Meyer et al. (2000). An increased stillbirth rate for both sexes (especially males) was found when sexed semen was compared with conventional semen by Norman et al. (2010). This is in contrast to other studies that have reported no identifiable effect (Seidel, 2007; Borchersen and Peacock, 2009; DeJarnette et al., 2009). The higher incidence of stillbirths among male calves born to sexsorted semen was also observed by DeJarnette et al. (2009). A suggested reason for the increased rate of stillbirths among sexed males compared with unsexed is that any Y-bearing spermatozoa included in the sorted X-bearing spermatozoa population will have a higher DNA content than normal Y-bearing spermatozoa (DeJarnette et al., 2009). These "aneuploid" sperm are therefore sorted as if they were X-bearing sperm, and it is postulated that the aneuploid condition may reduce calf viability and be responsible for an increased stillbirth rate (DeJarnette et al., 2009). In this study, we also observed an increased stillbirth rate in sexed heifers, suggesting that the sorting process damaged the sorted sperm, resulting in reduced fetal viability.
However, it would be logical to expect a concurrent increase in the abortion rate, which was not observed.

\section{Study Limitations}

A retrospective study has several limitations and sources of error, including reliance on the accuracy of on-farm records and lack of an insemination control group. The unsexed inseminations acted as a control, but were not subjected to the same conditions as sexed inseminations. A major source of bias was the preferential use of sexed straws at first and second service. It is therefore difficult to directly compare sexed and unsexed semen fertility, because the reduction in conception rates was not exclusively attributable to sorting.

This study was also limited to a single herd. Despite the fact that many of the findings of this study were consistent with the results of other studies, we cannot expect to accurately predict the general performance of sexed semen in Australian dairy herds due to the confounding influence of local factors specific to this farm. The study herd was significantly larger than the national average and it was also more intensively managed than most Australian dairy farms.

Another limitation was that this farm did not have sexed and unsexed straws from the same sires and so variation in the ability of individual bulls to withstand sexing and reduced doses could not be directly compared pre- and postsorting. A more accurate comparison of the fertility of sexed and unsexed sperm would require inseminations using sexed and unsexed straws from split ejaculates from the same bulls, with sperm viability examined before insemination.

A significant source of variation was the number of AI technicians employed and their differing skill levels. Neither semen handling nor technique was standardized among AI technicians. Additionally, the number of inseminations was not distributed evenly among technicians. One technician in particular performed substantially more sexed-straw inseminations than any of the other technicians. This technician also achieved the highest average conception rates, so it is likely that sexed straws were reserved for use by more experienced technicians.

The climate data for this farm were approximated using average temperature and humidity readings obtained from the 2 closest weather stations. This was therefore a source of variation in the study, because there will always be local weather variations not accounted for by the Cowra and Forbes weather stations. The timing of the temperature and humidity readings was also opportunistic (0900 and $1500 \mathrm{~h}$ ).

Approximation of heifer weight at breeding was a source of error and could explain why weight at breed- 
ing was not a significant predictor of conception rates, abortion, or stillbirths. The mean difference between weighing date and breeding date was $27 \mathrm{~d}$. However, in some cases, an interval of up to $89 \mathrm{~d}$ occurred between the last recorded weight and breeding. The average daily gain was only a target and we expect some variation around the approximation of $0.8 \mathrm{~kg} / \mathrm{d}$. Even if the estimated average daily gain were only slightly inaccurate, the adjusted weight at breeding would be imprecise for these animals with larger intervals.

Despite these limitations, many of the findings from this field application of sexed semen were consistent with the results of experimental trials.

\section{CONCLUSIONS}

Sexed semen enables farmers to increase the number of available replacement heifers; however, to optimize conception rates and the return on investment, sexed semen is best reserved for use in younger first-service heifers, during cooler months, and by more experienced technicians. In addition, because of variation in the ability of sires to withstand sorting, careful sire selection and monitoring of results will be important to maximize cost-to-benefit ratio. Sexed semen was of acceptable purity and resulted in no detectable abnormalities in the offspring. The marginally higher stillbirth rate observed in sexed calves requires further investigation to determine if the observed effect is repeatable.

\section{REFERENCES}

Andersson, M., J. Taponen, E. Koskinen, and M. Dahlbom. 2004. Effect of insemination with doses of 2 or 15 million frozen-thawed spermatozoa and semen deposition site on pregnancy rate in dairy cows. Theriogenology 61:1583-1588.

Bodmer, M., F. Janett, M. Hässig, N. d. Daas, P. Reichert, and R. Thun. 2005. Fertility in heifers and cows after low dose insemination with sex-sorted and non-sorted sperm under field conditions. Theriogenology 64:1647-1655.

Borchersen, S., and M. Peacock. 2009. Danish A.I. field data with sexed semen. Theriogenology 71:59-63.

Cerchiaro, I., M. Cassandro, R. Dal Zotto, P. Carnier, and L. Gallo. 2007. A field study on fertility and purity of sex-sorted cattle sperm. J. Dairy Sci. 90:2538-2542.

Chebel, R. C., F. A. Braga, and J. C. Dalton. 2007. Factors affecting reproductive performance of Holstein heifers. Anim. Reprod. Sci. 101:208-224.

De Vries, A., M. Overton, J. Fetrow, K. Leslie, S. Eicker, and G. Rogers. 2008. Exploring the impact of sexed semen on the structure of the dairy industry. J. Dairy Sci. 91:847-856.

DeJarnette, J. M., R. L. Nebel, and C. E. Marshall. 2009. Evaluating the success of sex-sorted semen in US dairy herds from on farm records. Theriogenology 71:49-58.

Donovan, G. A., F. L. Bennett, and F. S. Springer. 2003. Factors associated with first service conception in artificially inseminated nulliparous Holstein heifers. Theriogenology 60:67-75.

Erb, R. E., and R. A. Morrison. 1959. Effects of twinning on reproductive efficiency in a Holstein-Friesian herd. J. Dairy Sci. 42:512519 .
Fisher, L. J., and C. J. Williams. 1978. Effect of environmental factors and fetal and maternal genotype on gestation length and birthweight in Holstein calves. J. Dairy Sci. 61:1462-1467.

Frijters, A. C. J., E. Mullaart, R. M. G. Roelofs, R. P. van Hoorne, J. F. Moreno, O. Moreno, and J. S. Merton. 2009. What affects fertility of sexed bull semen more, low sperm dosage or the sorting process? Theriogenology 71:64-67.

Garner, D. L. 2006. Flow cytometric sexing of mammalian sperm. Theriogenology 65:943-957.

Garner, D. L., and G. E. Seidel Jr.. 2008. History of commercializing sexed semen for cattle. Theriogenology 69:886-895.

Hohenboken, W. D. 1999. Applications of sexed semen in cattle production. Theriogenology 52:1421-1433.

Mangurkar, B. R., J. F. Hayes, and J. E. Moxley. 1984. Effects of calving ease-calf survival on production and reproduction in Holsteins. J. Dairy Sci. 67:1496-1509.

Meyer, C. L., P. J. Berger, and K. J. Koehler. 2000. Interactions among factors affecting stillbirths in Holstein cattle in the United States. J. Dairy Sci. 83:2657-2663.

National Oceanic and Atmospheric Administration. 1976. Livestock hot weather stress. Regional Operations Manual Letter C-31-76. US Department of Commerce and National Oceanic and Atmospheric Administration, National Weather Service Central Region, Kansas City, MO.

Norman, H. D., J. L. Hutchison, and R. H. Miller. 2010. Use of sexed semen and its effect on conception rate, calf sex, dystocia, and stillbirth of Holsteins in the United States. J. Dairy Sci. 93:38803890.

Norman, H. D., J. R. Wright, M. T. Kuhn, S. M. Hubbard, J. B. Cole, and P. M. VanRaden. 2009. Genetic and environmental factors that affect gestation length in dairy cattle. J. Dairy Sci. 92:2259-2269.

Seidel, G. E., Jr. 2002. Sexing sperm for beef and dairy cattle breeding. Pages 281-286 in Factors Affecting Calf Crop: Biotechnology of Reproduction. CRC Press Inc., Boca Raton, FL.

Seidel, G. E. Jr. 2003. Sexing mammalian sperm - Intertwining of commerce, technology, and biology. Anim. Reprod. Sci. 79:145-156.

Seidel, G. E. Jr. 2007. Overview of sexing sperm. Theriogenology 68:443-446.

Seidel, G. E. Jr. 2008. Artificial insemination of cattle with sexed semen-Dealing with low numbers of slightly compromised sperm. Acta Sci. Vet. 36:283-286.

Seidel, G. E. Jr., and D. L. Garner. 2002. Current status of sexing mammalian spermatozoa. Reproduction 124:733-743.

Seidel, G. E. Jr., and J. L. Schenk. 2008. Pregnancy rates in cattle with cryopreserved sexed sperm: Effects of sperm numbers per inseminate and site of sperm deposition. Anim. Reprod. Sci. 105:129-138.

Seidel, G. E. Jr., J. L. Schenk, L. A. Herickhoff, S. P. Doyle, Z. Brink, R. D. Green, and D. G. Cran. 1999. Insemination of heifers with sexed sperm. Theriogenology 52:1407-1420.

Silva del Rio, N., S. Stewart, P. Rapnicki, Y. M. Chang, and P. M. Fricke. 2007. An observational analysis of twin births, calf sex ratio, and calf mortality in Holstein dairy cattle. J. Dairy Sci. 90:1255-1264

Stevenson, J. L., R. C. Chebel, J. C. Dalton, and J. E. P. Santos. 2006. Effect of synchronization protocols on reproductive performance of Holstein heifers. J. Anim. Sci. 84:210-211.

Tubman, L. M., Z. Brink, T. K. Suh, and G. E. Seidel Jr. 2004. Characteristics of calves produced with sperm sexed by flow cytometry/ cell sorting. J. Anim. Sci. 82:1029-1036.

Vazquez, J. M., I. Parrilla, M. A. Gil, C. Cuello, I. Caballero, J. L. Vazquez, J. Roca, and E. A. Martinez. 2008. Improving the efficiency of insemination with sex-sorted spermatozoa. Reprod. Domest. Anim. 43:1-8.

Weigel, K. A. 2004. Exploring the role of sexed semen in dairy production systems. J. Dairy Sci. 87(Suppl. 13):120-130. 